NOTE

\title{
Synthesis of New Monomers by Addition Reactions of Diethylamine to meta-Divinylbenzene Catalyzed by Lithium Diethylamide
}

\author{
Joei Yukawa, Kazunori KataOKa, Yoshiaki Nitadori, \\ and Teiji Tsuruta \\ Department of Synthetic Chemistry, Faculty of Engineering, University of Tokyo, \\ Hongo, Bunkyo-ku, Tokyo 113, Japan.
}

(Received June 6, 1978)

\begin{abstract}
KEY WORDS 1,3-Divinylbenzene / 1-(2-Diethylaminoethyl)-3-vinylbenzene / Lithium Diethylamide / Nucleophilic Addition Reaction / ${ }^{13} \mathrm{C} \mathrm{NMR} /$
\end{abstract}

In a previous paper, ${ }^{1}$ it was reported that $p$ divinylbenzene ( $p$-DVB) reacted with diethylamine in the presence of lithium diethylamide to give $p$ diethylaminoethylstyrene ( $p$-EAS). A series of functional polymers can be prepared with $p$-EAS as the starting monomer. Evaluation of these polymers as biomaterials are now being carried out under the cooperation of Prof. Y. Sakurai and Dr. T. Akaike, Tokyo Women's Medical College. For instance, a polyion complex prepared by combining quaternized poly( $p$-EAS) with poly(sodium styrenesulfonate) exhibited a unique interfacial behavior in a blood stream. ${ }^{2}$

One of our primary objects is to elucidate the structural factors determining the biocompatibility of a synthetic material. It was therefore desirable for us to study the biomedical behaviors of polymers derived from $m$-EAS in comparison with those from $p$-EAS.

This paper is concerned with the synthesis of $m$-EAS. The reactivity of lithium diethylamide toward a series of styrene derivatives is also reported.

\section{EXPERIMENTAL}

\section{Materials}

$m$-DVB was prepared as follows. Commercial DVB mixture was brominated. The precipitate of $p$-divinylbenzene tetrabromide was separated by filtration. ${ }^{3}$ The filtrate was concentrated and then allowed to stand in a refrigerator until the crude $m$-divinylbenzene tetrabromide was crystallized. The bromide was recrystallized from an ethanol solution ${ }^{4}$ and then debrominated with zinc powder. $^{3} \quad$ The purity of $m$-DVB was determined by means of vapor phase gas chromatography to be more than $99 \%$. Cyclohexane and diethylamine were purified by usual methods. Butyllithium was prepared from butyl chloride and lithium metal in purified petroleum ether and was used as a cyclohexane solution.

Synthesis of 1-(2-Diethylaminoethyl)-3-vinylbenzene (m-Diethylaminoethylstyrene, $m$-EAS)

To the cyclohexane $(80 \mathrm{~m} l)$ solution of $m$-DVB $(400 \mathrm{mmol})$, the amide - amine complex, prepared from $440 \mathrm{mmol}$ of diethylamine and $8 \mathrm{mmol}$ of butyllithium, was added. The mixture was heated at $50^{\circ} \mathrm{C}$ for $80 \mathrm{~min}$. Then, a small amount of methanol was added to cease the reaction. After the solvent and other low boiling point materials were removed by evaporation, $m$-EAS was separated by a fractional distillation in vacuo; bp $70^{\circ} \mathrm{C}(0.05 \mathrm{~mm})$. The yield of $m$-EAS based on $m$-DVB was $75 \mathrm{~mol} \%$. 1, 3-Bis(2-diethylaminoethyl)benzene ( $m$-BEAB) was also obtained (yield $15 \mathrm{~mol} \%)$; bp $108^{\circ} \mathrm{C}(0.08 \mathrm{~mm})$.

\section{Rate Study}

The methods of rate study of the addition reaction were described in a previous paper. ${ }^{5}$

\footnotetext{
${ }^{13} \mathrm{C}$-NMR Measurement

${ }^{13} \mathrm{C}$-NMR measurements were carried out by
} means of a JEOL PFT-100 spectrometer. 


\section{RESULTS AND DISCUSSION}

In previous studies, ${ }^{5-7}$ it was established that a 1:2 complex consisting of lithium diethylamide and diethylamine was the reacting species in the addition reaction with butadiene, isoprene and styrene. The overall rate of these reactions was expressed by eq 1 .

$$
v=k\left[\text { vinyl] }\left[\mathrm{Et}_{2} \mathrm{NLi}\right]\right.
$$

where $k$ stands for a second-order rate constant, [vinyl] for the concentration of a vinyl compound, and $\left[\mathrm{Et}_{2} \mathrm{NLi}\right]$ for that of lithium diethylamide. The following reaction schemes for $m$-DVB were examined by kinetic measurements.

$$
\begin{aligned}
& \left.\left.\mathrm{Et}_{2} \mathrm{NLi}_{2} \cdot 2 \mathrm{Et}_{2} \mathrm{NH}+\mathrm{CH}_{2}=\mathrm{CH}-\mathrm{O}\right\}^{\mathrm{CH}=\mathrm{CH}_{2}} \stackrel{k_{1}}{\longrightarrow} \mathrm{Et}_{2} \mathrm{NCH}_{2} \mathrm{CHLi}-\mathrm{O}\right\}^{\mathrm{CH}=\mathrm{CH}_{2}} \cdot 2 \mathrm{Et}_{2} \mathrm{NH} \\
& \left.\mathrm{Et}_{2} \mathrm{NCH}_{2} \mathrm{CHLi}-\mathrm{O}\right\rangle^{\mathrm{CH}=\mathrm{CH}_{2}} \cdot 2 \mathrm{Et}_{2} \mathrm{NH}+\mathrm{Et}_{2} \mathrm{NH} \stackrel{\text { fast }}{\longrightarrow} \mathrm{Et}_{2} \mathrm{NCH}_{2} \mathrm{CH}_{2}-O{ }^{\mathrm{CH}=\mathrm{CH}_{2}}+\mathrm{Et}_{2} \mathrm{NLi}^{-2 \mathrm{Et}_{2} \mathrm{NH}} \\
& \left.\mathrm{Et}_{2} \mathrm{NLi}_{2} \cdot 2 \mathrm{Et}_{2} \mathrm{NH}+\mathrm{Et}_{2} \mathrm{NCH}_{2} \mathrm{CH}_{2}-\mathrm{O}\right)^{\mathrm{CH}=\mathrm{CH}_{2}} \stackrel{k_{2}}{\longrightarrow} \mathrm{Et}_{2} \mathrm{NCH}_{2} \mathrm{CH}_{2}-\mathrm{O}^{\mathrm{CHLiCH}_{2} \mathrm{NEt}_{2}} \cdot 2 \mathrm{Et}_{2} \mathrm{NH}^{-} \\
& \mathrm{Et}_{2} \mathrm{NCH}_{2} \mathrm{CH}_{2}-\mathrm{O} \stackrel{\text { fast }}{\longrightarrow}
\end{aligned}
$$

$$
\mathrm{Et}_{2} \mathrm{NCH}_{2} \mathrm{CH}_{2}-\mathrm{O} \overbrace{}^{\mathrm{CH}_{2} \mathrm{CH}_{2} \mathrm{NEt}_{2}}+\mathrm{Et}_{2} \mathrm{NLi}_{2} \cdot 2 \mathrm{Et}_{2} \mathrm{NH}
$$

As shown in Figures 1 to 4 , eq 1 is also applicable to these reaction systems, where $k_{1}$ was $5.2 \times$ $10^{-3} l \mathrm{~mol}^{-1} \mathrm{~s}^{-1}$ and $k_{2}$ was $9.8 \times 10^{-4} l \mathrm{~mol}^{-1} \mathrm{~s}^{-1}$. These values are compared with those of paraderivatives in Table I. The $k / 2$ values are listed

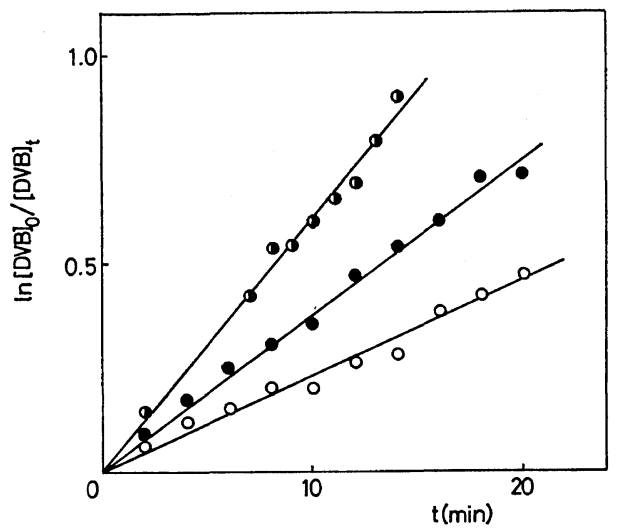

Figure 1. First-order analysis of the reaction of $\mathrm{Et}_{2} \mathrm{NH}-\mathrm{Et}_{2} \mathrm{NLi}$ complex with $m$-divinylbenzene: $[m-\mathrm{DVB}]_{0}=0.125 \mathrm{~mol} / l ; \quad\left[\mathrm{Et}_{2} \mathrm{NH}\right]_{0} /\left[\mathrm{Et}_{2} \mathrm{NLi}_{0}=10 ;\right.$ $\left[\mathrm{Et}_{2} \mathrm{NLi}\right]_{0}=0.20 \mathrm{~mol} / l(\circlearrowleft), 0.125 \mathrm{~mol} / l(\bullet)$, and 0.07 $\mathrm{mol} / \mathrm{l}(\mathrm{O})$ in cyclohexane at $50^{\circ} \mathrm{C}$. for $p$-DVB and $m$-DVB in Table I since each has two vinyl groups.

As described in the experimental part, $m$-EAS can be prepared selectively although the selectivity was somewhat lower than in the para-derivative. As seen in Table I, the reactivity of $m$-DVB toward lithium diethylamide is $\mathbf{3}$ times higher than that of

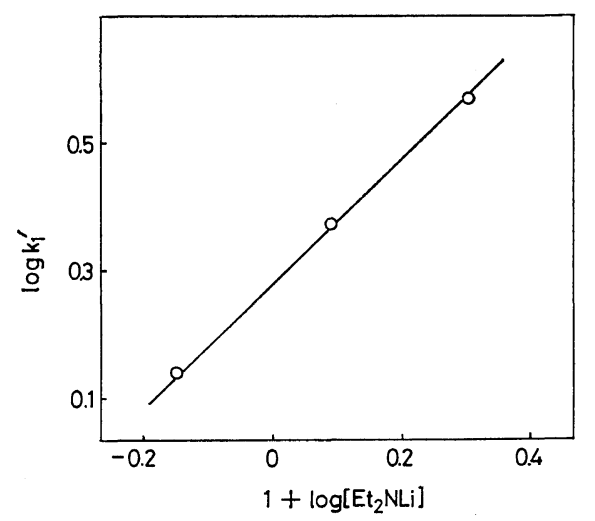

Figure 2. Relationship between lithium diethylamide concentration and the pseudo-first-order rate constant $k_{1}{ }^{\prime}$. 


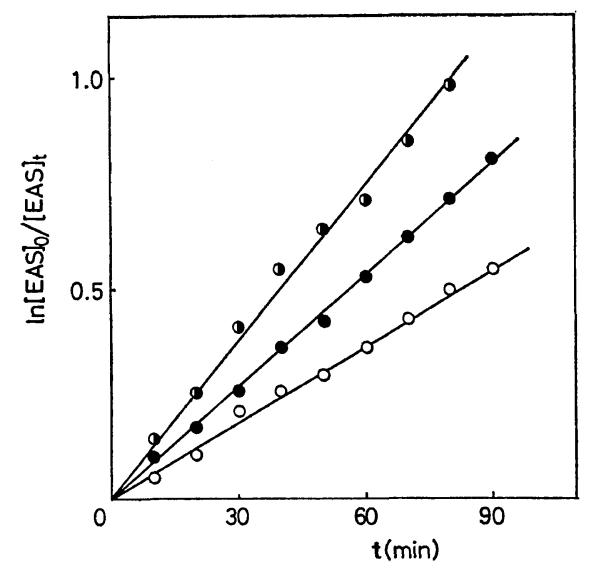

Figure 3. First-order analysis of the reaction of $\mathrm{Et}_{2} \mathrm{NH}-\mathrm{Et}_{2} \mathrm{NLi}$ complex with $m$-diethylaminoethylstyrene: $[m-\mathrm{EAS}]_{0}=0.25 \mathrm{~mol} / l ;\left[\mathrm{Et}_{2} \mathrm{NH}\right]_{0} /\left[\mathrm{Et}_{2} \mathrm{NLi}\right]_{0}=$ $10 ;\left[\mathrm{Et}_{2} \mathrm{NLi}\right]_{0}=0.20 \mathrm{~mol} / l(\circlearrowleft), \quad 0.15 \mathrm{~mol} / l(\odot)$, and $0.10 \mathrm{~mol} / \mathrm{l}(\mathrm{O})$ in cyclohexane at $50^{\circ} \mathrm{C}$.

$m$-EAS, while the reactivity of $p$-DVB is 10 times higher than that of $p$-EAS.

The ${ }^{13} \mathrm{C}$-NMR spectra were measured in cyclohexane. The chemical shifts of $\beta$-carbon are listed in Table I. A linear relationship, except for $p$ DVB, was observed between $\log k$ and the chemical shift of $\beta$-carbon as shown in Figure 5. This result suggests that each vinyl group in $m$-DVB may conjugate with the aromatic electron system

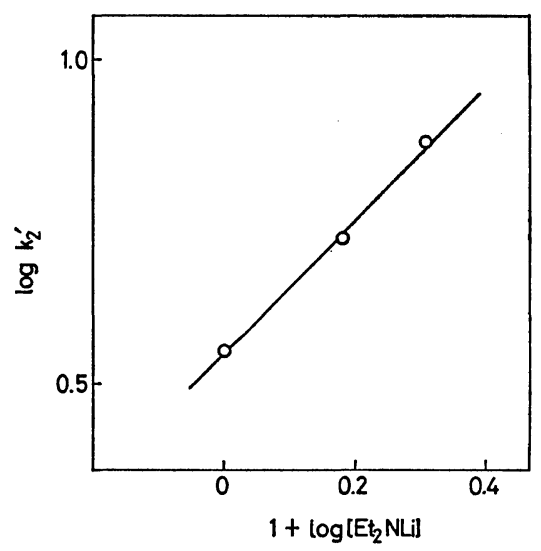

Figure 4. Relationship between lithium diethylamide concentration and the pseudo-first-order rate constant $k_{2}{ }^{\prime}$.

independently. In other words, the conjugation system of $m$-DVB can be regarded as the 8membered system in the same way as in styrene, $m$-EAS and $p$-EAS, in contrast with the 10 -membered system of $p$-DVB. Therefore, the reactivity of $p$-DVB should not be discussed in terms of the same linear relationship as the one that holds in the other styrene derivatives. The negative slope of the straight line in Figure 5 shows that the addition reaction of lithium diethylamide has a nucleophilic character as reported previously. ${ }^{7}$

Table I. The second-order rate constants $k$ of the addition reaction and ${ }^{13} \mathrm{C}$ chemical shift of $\beta$ carbon of styrene derivatives

\begin{tabular}{|c|c|c|c|}
\hline Styrene derivatives & $\begin{array}{c}k, \\
l \mathrm{~mol}^{-1} \mathrm{~s}^{-1}\end{array}$ & $\begin{array}{c}{ }^{13} \mathrm{C} \text { chemical }{ }^{\mathrm{b}} \\
\text { shift of } \beta \text {-carbon }\end{array}$ & Ref \\
\hline $\mathrm{CH}_{2}=\mathrm{C}$ & $4.35 \times 10^{-3}$ & 113.12 & 1 \\
\hline $\mathrm{CH}_{2}=\mathrm{C}$ & $2.6 \times 10^{-3}$ & 113.43 & This work \\
\hline $\mathrm{CH}_{2}=\mathrm{C}$ & $1.6 \times 10^{-3}$ & 113.18 & 5 \\
\hline $\mathrm{CH}_{2}=\mathrm{C}$ & $9.8 \times 10^{-4}$ & 112.83 & This work \\
\hline $\mathrm{CH}_{2}=\mathrm{Cr}$ & $4.3 \times 10^{-4}$ & 112.28 & 1 \\
\hline
\end{tabular}

a $k / 2$ values are listed.

b In a cyclohexane solution, ppm from TMS. 
J. Yukawa, K. Kataoka, Y. Nitadori, and T. Tsuruta

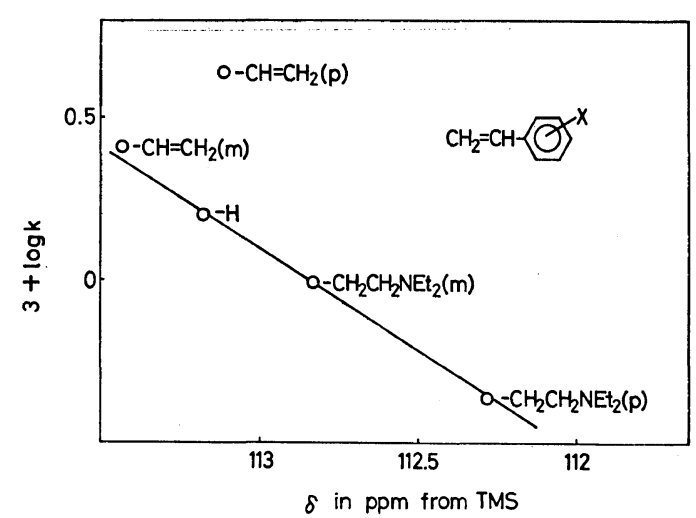

Figure 5. Relationship between the reactivity of styrene derivatives in their reaction with the $\mathrm{Et}_{2} \mathrm{NH}-$ $\mathrm{Et}_{2} \mathrm{NLi}$ complex and ${ }^{13} \mathrm{C}$ chemical shift of their $\beta$ carbon.
Homopolymerization of $m$-EAS and copolymerizations of $p$-EAS and of $m$-EAS will be reported elsewhere.

\section{REFERENCES}

1. T. Tsuruta, T. Narita, Y. Nitadori, and T. Irie, Makromol. Chem., 177, 3255 (1976).

2. K. Kataoka, T. Akaike, Y. Sakurai, and T. Tsuruta, Makromol. Chem., 179, 1121 (1978).

3. B. T. Storey, J. Polym. Sci., Part A, 3, 265 (1965).

4. Beilstein III 5, 967.

5. T. Narita, N. Imai, and T. Tsuruta, Bull. Chem. Soc. Jpn., 46, 1242 (1973).

6. T. Narita, Y. Nitadori, and T. Tsuruta, Polym. J., 9, 191 (1977).

7. T. Narita, T. Yamaguchi, and T. Tsuruta, Bull. Chem. Soc. Jpn., 46, 3825 (1973). 